\title{
Estudo comparativo entre materiais a base de vidro e policarbonato em projetos de superfícies transparentes
}

\author{
Comparative study between glass and polycarbonate based \\ materials in transparent surface projects
}

\author{
Amanda Cristina Rustici Balsamo ${ }^{1}$; Bruna Vieira Cabral ${ }^{2}$; Rafaela Cristina Sanfelice ${ }^{3}$ \\ ${ }^{1}$ Aluna do Curso de Graduação em Engenharia Química, Universidade Federal do Triângulo Mineiro, \\ Uberaba, Minas Gerais, Brasil. E-mail: amanda.rustici@outlook.com \\ ${ }^{2}$ Professora do Departamento de Engenharia Ambiental, Universidade Federal do Triângulo Mineiro, \\ Uberaba, Minas Gerais, Brasil. E-mail: brunacabral.uftm@gmail.br \\ ${ }^{3}$ Professora do Programa de Mestrado em Inovação Tecnológica, Universidade Federal do Triângulo \\ Mineiro, Uberaba, Minas Gerais, Brasil. E-mail: rafaela.sanfelice@uftm.edu.br
}

\begin{abstract}
RESUMO: Projetar áreas com coberturas ou grandes janelas transparentes é considerado um desafio devido ao comportamento da radiação solar que impede, muitas vezes, atingir um nível adequado de iluminação e carga térmica. É possível proporcionar conforto térmico dentro de projetos quando há escolha correta dos materiais de construção, disposição adequada das aberturas e sombreamentos, garantindo insolação e ventilação adequadas. Além do conforto térmico o uso da luz natural pode gerar uma economia de energia elétrica. Dentre os materiais empregados nesses projetos encontra-se os vidros e os policarbonatos. Alguns vidros podem ser utilizados em temperaturas extremas e exibir diversos graus de resistência mecânica. $O$ vidro se mostrou ser muito eficiente devido ao comportamento das radiações solares em contato com ele, também é um material resistente às soluções ácidas e levemente básicas. Os policarbonatos são polímeros termoplásticos de cadeia heterogênea linear, que possuem transparência similar ao vidro e além de ter resistência ao impacto superior que o vidro é muito bom em situações de incêndio. $O$ objetivo do trabalho é desenvolver um comparativo entre materiais a base de vidro e o policarbonato em projetos de superfícies transparentes, analisando a economia energética e conforto, usando parâmetros como: resistência térmica, resistência ao impacto, comportamento frente a radiações e compostos químicos, estabilidade e durabilidade química.
\end{abstract}

Palavras-chave: Vidros; Policarbonatos; Resistência; Conforto térmico; Radiação Solar.

ABSTRACT: The design of areas with transparent cover or large transparent windows is considered a challenge due to the behavior of solar radiation that often does not allow adequate thermal comfort inside projects. When there is a correct choice of building materials, adequate arrangement of openings and shading, adequate sunshine and ventilation it is possible to ensure the success of the design. In addition to thermal comfort, the use of natural light can promote energy savings. The most used materials in these kind of projects are the glass and polycarbonate derivatives. Some glass materials can be used in very high temperatures and can exhibit a range of mechanical strength. Glass shows an efficiency in relation to solar radiation and it is resistant to acidic and slightly basic solutions. Polycarbonates are thermoplastic polymers with linear heterogeneous chain, which have glasslike transparency, superior impact resistance, and they are resistant to in fire. This work was based on develop of a comparison between glass and polycarbonate derivatives materials in transparent surface designs, with analyze of energy savings and thermal comfort. The studies were realized using parameters such as thermal resistance, impact resistance, behavior against radiation and chemical compounds, stability and chemical durability.

Keywords: Glass; Polycarbonates; Resistance; Thermal comfort; Solar radiation.

DOI: $10.18554 /$ rbcti.v4i3.3904 


\section{INTRODUÇÃO}

Com o progresso das técnicas de construção civil, aumentou-se o interesse em diferentes formas de coberturas, ganhando cada vez mais expressão arquitetônica. Além de ser um refúgio para ações climáticas também desenvolvem um papel estético nas construções civis, buscando sempre por inovação, melhora das técnicas (reduzindo o tempo de execução) e utilizando materiais mais eficientes para execução (RIFFEL et al., 2017).

Hoje em dia, a criação de áreas com coberturas transparentes é considerada um desafio devido a penetração da radiação solar que, muitas vezes, não atinge um nível adequado de iluminação e carga térmica. Áreas revestidas com materiais transparentes ou translúcidos oferecem maiores níveis de iluminação natural, porém permitem excessivos ganhos ou perdas de calor e consequentemente elevam o consumo de energia elétrica, devido ao uso dos meios artificiais para resfriamento ou aquecimento do ambiente. É possível proporcionar conforto térmico dentro de projetos de cobertura quando há escolha correta dos materiais de construção e a disposição adequada das aberturas e sombreamentos, garantindo insolação e ventilação adequadas. Os materiais mais utilizados nesses projetos são os vidros e os policarbonatos (PAIXÃO; CASTRO, 2011).

A primeira forma industrial do vidro surgiu na idade de 7.000 a.c. na Síria, Palestina, Mesopotâmia e na China. O material era moldado sobre a areia e possuía aparência fosca. Já os árabes foram os primeiros precursores do vidro transparente. Até 1.500 a.c. o vidro era utilizado como enfeite, e possuía pouca utilidade prática. Em 300 a.c. foi desenvolvida a técnica de sopro, que é utilizada até os dias de hoje, e tem como objetivo moldar o vidro e transformá-lo em frascos e recipientes (BARROS; VIANA, 2010).

Fisicamente, o vidro é considerado um líquido super-resfriado, em grande maioria não biodegradáveis e não tem um ponto de fusão definido, mas tem uma viscosidade muito alta. Alguns vidros podem ser utilizados em temperaturas extremas e exibir diversos graus de resistência mecânica, ser densos ou leves, impermeáveis ou porosos. Alguns materiais podem sofrer variações bruscas de temperatura sem que ocorram alterações dimensionais ou trincas. São normalmente isolantes elétricos e térmicos (AKERMAN, 2013).

O vidro é considerado um material $100 \%$ reciclável e é formado essencialmente de matérias-primas naturais e abundantes ilustrados na Figura 1 (CEBRACE ENCICLOPEDIA, 2019).

No Brasil, cerca de $47 \%$ das embalagens de vidro foram recicladas em 2011 , sendo $40 \%$ oriundo da indústria de envaze, $40 \%$ do mercado difuso, $10 \%$ do "canal frio" (bares, restaurantes, hotéis etc.) e $10 \%$ do refugo da indústria. Na Tabela 1 pode-se ver algumas aplicações do vidro no dia a dia. O país produz em média 980 mil toneladas de embalagens de vidro por ano, usando cerca de $45 \%$ de matéria-prima reciclada na forma de cacos. Parte deles foi gerado como refugo nas fábricas e parte retornou por meio da coleta seletiva (IMBELLONI, 2011) 
Figura 1. Relação entre as porcentagens dos componentes do vidro silicato comercial (Cebrace Enciclopedia 2019).

\title{
Percentual de Componentes que Compõe o Vidro
}

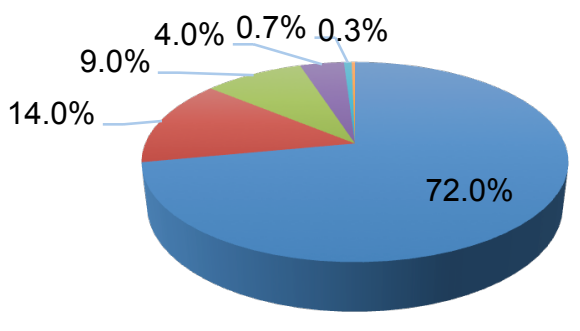

\author{
Dióxido de silício \\ (Sílica) \\ - Sulfato de Sódio \\ Óxido de Cálcio (Cal) \\ - Óxido de Magnésio
}

Tabela 1. Diferentes tipos de vidros usados em diferentes aplicações cotidianas.

\begin{tabular}{cc}
\hline Tipos & Aplicações \\
\hline $\begin{array}{c}\text { Vidro para } \\
\text { embalagens } \\
\text { Vidro plano }\end{array}$ & Garrafas, potes, frascos \\
Vidros domésticos & Janelas, de automóveis, fogões e micro-ondas \\
Fibras de vidro & Travessas, copos, pratos e panelas. \\
Vidros técnicos & Mantas, tecidos e fios. \\
\hline
\end{tabular}

Fonte: Recicloteca, 2017

Os vidros laminados e temperados são os mais usados em instalações para coberturas e fechamentos que exigem iluminação natural, por apresentarem maior resistência ao impacto, transparência e durabilidade. Os acabamentos de telhados de vidro, na maioria das vezes, são instalados com o auxílio de peças em inox ou em esquadrias de alumínio proporcionando uma aparência mais leve e elegante ao ambiente. A instalação de um telhado de vidro normalmente possui um custo semelhante à de um telhado convencional, pois usa o mesmo tipo de estrutura e mão de obra (BELARMINO, 2015).

Os policarbonatos começaram a ser fabricados industrialmente em 1953 pela Bayer e General Electric independentemente. São polímeros termoplásticos amorfos, de cadeia heterogênea linear, originários da condensação do bisfenol A e do ácido carbônico (SARDEIRO, 2009; SARDEIRO; CARAM, 2009). Eles possuem transparência similar ao vidro e maior resistência ao impacto. Em projetos de construção civil, a resistência ao impacto proporciona proteção eficaz contra vandalismo e roubos. Para alguns autores, o uso do policarbonato não é adequado, por não trazer um equilíbrio entre as áreas opacas e transparentes nos projetos de edificações (PAIXÃO; CASTRO, 2011).

Na Figura 2 está ilustrada a estrutura química do policarbonato. O mesmo é obtido por processos "melt-phase" que foi desenvolvido na década de noventa. As resinas são produzidas em sua maioria via reação de policondensação, desenvolvido pelo pioneirismo da Bayer Material Science e a GE Plastics (atualmente Sabic Innovative Plastics), 
envolvendo a reação de BPA (bisfenol A) com Fosgênio $\left(\mathrm{COCl}_{2}\right)$.

Figura 2. Estrutura química da unidade repetitiva do policarbonato.

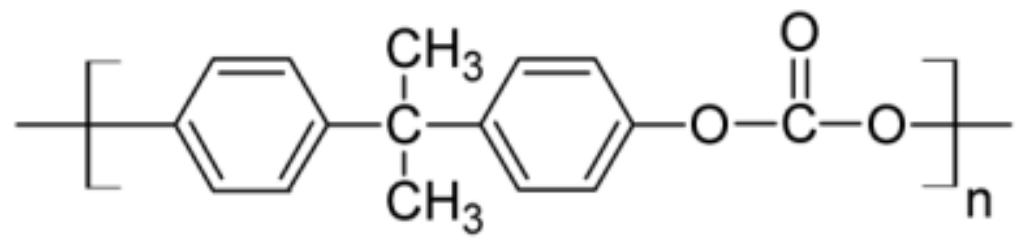

Fonte: Resinex Group, 2019

O policarbonato reúne algumas propriedades de metais leves, de vidros e de plásticos, sendo algumas delas a resistência a choques, flexão, transparência dentre outras. Por isso, são usados na fabricação de janelas de avião e "vidros à prova de balas", além de outros produtos tais como lentes, mamadeira, CD's (PIATTI; RODRIGUES, 2005). Na Tabela 2 pode-se resumir algumas das principais aplicações dos policarbonatos.

Tabela 2. Diferentes tipos de aplicações do Policarbonato em diferentes áreas

\begin{tabular}{cc}
\hline Tipos & Aplicações \\
\hline Projetos residenciais & $\begin{array}{r}\text { Coberturas, claraboias lisas e curvas, janelas e } \\
\text { basculantes }\end{array}$ \\
Projetos comerciais & $\begin{array}{r}\text { Shopping centers, hotéis, restaurantes, entradas } \\
\text { sociais, escolas, hospitais }\end{array}$ \\
Projetos industriais & $\begin{array}{c}\text { Coberturas de galpões, proteção p/ máquinas, } \\
\text { viseiras e capacetes, isolantes acústicos. } \\
\text { Ônibus, trens, metrô, carros fortes, interior de } \\
\text { Transportes }\end{array}$ \\
& $\begin{array}{c}\text { aeronaves e embarcações, blindagem de veículos, } \\
\text { lanternas, faróis, para-choques, painéis e outras } \\
\text { peças de automóveis. }\end{array}$ \\
& $\begin{array}{c}\text { Escudos de proteção, letreiros em estradas, } \\
\text { componentes elétricos e eletrônicos, CD's, }\end{array}$ \\
Outros & conectores, recipientes para fornos de micro-ondas. \\
\hline
\end{tabular}

Fonte: Portal, 2019

Devido aos diferenciados usos do policarbonato, o mesmo pode ser reaproveitado na reutilização e através de reciclagem química ou mecânica. Na reciclagem química o policarbonato pode ser completamente decomposto em bisfenol $A$, através do uso de uma alta pressão e alta temperatura, e na reciclagem mecânica, considerada mais comum e simples, o material passa pelas etapas de moagem, lavagem, secagem, aglutinação e reprocessamento, dando origem ao grânulo ou a uma peça. Pode também envolver a aditivação (VIEIRA, 2014).

O conforto térmico é definido através de diferentes sensações humanas, e situa-se no campo do subjetivo e depende de fatores físicos, fisiológicos e psicológicos. Os estudos em conforto térmico estão baseados principalmente em 3 fatores; satisfação do homem ou seu bem-estar em se sentir termicamente confortável, a performance humana 
onde estudos mostram uma clara tendência de que o desconforto causado por calor ou frio reduz a performance humana, e a conservação de energia onde diz que as pessoas passam grande parte de suas vidas em ambientes condicionados artificialmente devido a crescente mecanização e industrialização. Todos esses fatores visam principalmente analisar e estabelecer as condições necessárias para a avaliação e concepção de um ambiente térmico adequado às atividades e ocupação humanas, bem como estabelecer métodos e princípios para uma detalhada análise térmica de um ambiente (LAMBERTS; AUGUSTO; VECCHI, 2012).

Com essa abordagem, o trabalho tem como objetivo fazer um comparativo entre o vidro e o policarbonato em projetos de superfícies transparentes, abordando assuntos como a resistência térmica do material, resistência ao impacto, comportamento frente a radiações e compostos químicos, analisando sua estabilidade química e durabilidade, e por fim analisar a economia energética que a cobertura transparente traz ao utilizar a luz natural para iluminação e qual material pode garantir um melhor conforto térmico e luminoso.

\section{MÉTODO}

Este trabalho foi realizado através da pesquisa bibliográfica na literatura sobre a comparação entre os materiais vidro e policarbonato, e foram utilizados como parâmetros de comparação o conforto térmico e economia energética, a resistência térmica do material, resistência ao impacto, durabilidade e a sua estabilidade química. Foram selecionados artigos nacionais e internacionais encontrados nas seguintes plataformas:

- SciELO

- Google Scholar

- Science direct

- Web of Science

As principais palavras chaves utilizadas nas buscas dos artigos foram em língua portuguesa e inglesa e foram encontrados resultados significativos para as seguintes palavras: Projetos de Construção (Construction projects), Resistência (Resistance), Transparência (Transparency), Policarbonatos (Polymers) e Vidros (Glass).

\section{DESENVOLVIMENTO}

\section{LUZ NATURAL, CONFORTO E ECONOMIA ENERGÉTICA}

Toledo (2008) destaca que a relação entre luz e espaço determina a nossa percepção visual do mundo. Durante milhões de anos a visão humana evoluiu usando a luz natural e, em vista disso, possui uma maior facilidade de se adaptar a ela. A presença da luz natural e difusa no ambiente possui variedade com a mudança de cores, contrastes e luminosidade. Sardeiro (2007) diz que a qualidade espectral da luz, influencia na aparência das cores; mesmo com os avanços da tecnologia, a luz natural é considerada a melhor na reprodução das cores, tendo o sentido humano de visão como referência.

Para aproveitar a iluminação natural em um edifício, o sistema de iluminação artificial deve desligar ou reduzir a intensidade nos momentos em que a iluminação natural for suficiente. A economia de energia elétrica pode ser significativa quando a luz natural atuar em conjunto com o sistema de controle de luz artificial (TOLEDO, 2008). 
Em consequência da crise energética da década de 70, a luz solar começou a ser levada em consideração como uma técnica potencial para a iluminação e economia de energia. O total da produção nacional de energia elétrica, $23 \%$ é destinada ao uso em arquitetura residencial e cerca de $16 \%$ do total de energia elétrica consumida no país é para iluminação. A economia só acontece quando a carga de iluminação artificial pode ser reduzida e a utilização da luz natural pode reduzir o consumo de energia elétrica em cerca de $50 \%$ (SARDEIRO, 2007).

De acordo com o Anuário Estatístico de Energia Elétrica de 2018, em 2017, o consumo de eletricidade no país cresceu 1,2\% em relação a 2016, alcançando 467 TWh, mantendo o Brasil entre os dez maiores consumidores do mundo. O setor industrial segue sendo o maior consumidor, com quase $36 \%$ do total, seguido do setor residencial, com cerca de $29 \%$. As regiões Sul e Centro Oeste lideraram o crescimento, com taxas de $3,1 \%$ e $2,4 \%$, mas a região Sudeste segue sendo a região de maior participação no consumo do país, representando praticamente $50 \%$ do total (BRASIL, 2018).

Portanto, entrando no contexto de sustentabilidade, para se ter uma edificação energética eficiente, o projeto de iluminação deve buscar o máximo aproveitamento da luz natural e, se necessário, complementar com iluminação artificial, possibilitado uma redução no consumo de energia elétrica e proporcionando um conforto visual aos usuários. Mas é importante destacar que possibilitando a maior entrada de luz natural, implica maiores ganhos e perdas de carga térmica da edificação, que se refletem na demanda energética do sistema de condicionamento de ar (MALLMANN, 2011). As ações para integração entre luz natural e artificial estão ilustradas na Tabela 3.

Tabela 3. Ações para integração entre luz natural e artificial em projetos de construção.

Ações

Estratégia de controle (automação)

Layout das luminárias

Escolha de Materiais

\section{Descrição}

Determinação da estratégia de controle (automação) que fará a ligação entre a disponibilidade de luz natural e o sistema de iluminação artificial (MALLMANN, 2011).

Estabelecimento do layout das luminárias em sistemas independentes, de forma a complementar a luz natural ou atuar quando esta não estiver disponível (MALLMANN, 2011).

Escolha de lâmpadas e acessórios energeticamente eficientes Escolha das luminárias apropriadas à estratégia de controle (automação) (MALLMANN, 2011).

Para um projeto de coberturas de edificações, devemos ter em mente que a radiação solar incidente sobre uma superfície, terá uma parcela absorvida, uma refletida e outra transmitida. Em fechamentos opacos não há transmissividade, sendo uma superfície com absortividade de $80 \%$ necessariamente apresentará um valor de refletividade de $20 \%$. Em fechamentos transparentes, vidros principalmente, ocorre absorção e reflexão de forma semelhante à dos fechamentos opacos, porém acrescida de uma parcela da radiação que é diretamente transmitida para o meio interno (MALLMANN, 2011).

Quando se fala em penetração da luz natural em ambientes fechados, é necessário ter cuidado ao especificar uma superfície transparente ou translúcida. Para a escolha do 
material, devemos ter cuidado com a sua dimensão, orientação, e o uso de proteção solares externas, pois a radiação solar que passa através da superfície transparente pode aquecer os objetos que se encontram no ambiente interno. Alguns trabalhos afirmam que o aquecimento excessivo por razão das superfícies transparentes é causado por efeito estufa, pois o calor gerado no ambiente interno não atravessa totalmente 0 vidro ou 0 policarbonato, sendo assim, acumulado no ambiente.

Com o auxílio da Figura 3, podemos compreender melhor o que acontece com a luz que penetra nos ambientes através de coberturas transparentes. Na Figura 3-a observamos que parte da energia transmitida pela radiação solar que incide em uma cobertura transparente vai diretamente para o interior do ambiente e parte é refletida ou absorvida pelo material. Na Figura 3-b observamos que a radiação que penetrar em uma cobertura translúcida difunde-se e sai como uma luz difusa e não direta, como ocorre no material transparente, pois uma parcela da energia é refletida (SARDEIRO; CARAM, 2009).

Figura 3 - Comparação do comportamento da radiação em superfícies transparentes e translúcidas do vidro.

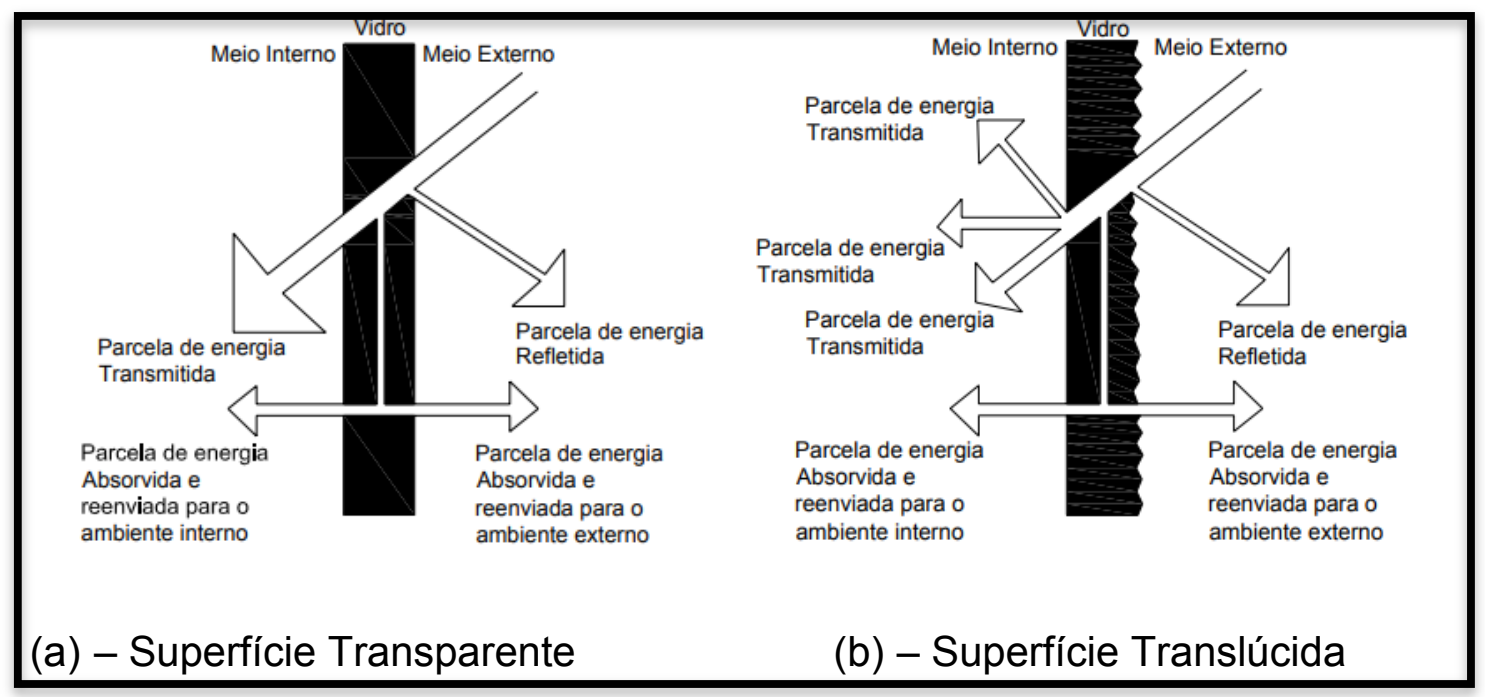

Fonte: Sardeiro e Caram, 2009

Portanto, pode-se observar que a transmissão nos materiais translúcidos é bem inferior quando comparada com os materiais transparentes; em virtude disso, ocasiona um menor ganho de calor no interior da edificação (SARDEIRO; CARAM, 2009).

Em relação as temperaturas das superfícies dos materiais e a resposta térmica do ambiente interno, Paixão (2011), em sua análise do desempenho térmico do policarbonato e acrílico, afirmou que no verão a temperatura da superfície externa do policarbonato se mantem na maior parte do dia superior em relação à temperatura superficial interna, diferentemente do que aconteceu no período de inverno que a superfície interna do policarbonato apresentou temperaturas mais elevadas do que as temperaturas da superfície externa, e isso acontece pois a temperatura do ar no inverno é inferior à temperatura do ar no período de verão, quando a velocidade do ar aumenta acontece o resfriamento da temperatura da superfície externa do policarbonato, e devido suas propriedades de isolamento térmico, o ar no ambiente interno continua aquecido e mantém a temperatura da superfície interna do material elevada. 
Em seu trabalho, (SANTOS et al., 2018) observou que todos os policarbonatos ensaiados em sua pesquisa transmitiam uma parcela muito pequena no UV, e que a maioria deles transmitia maior percentual de energia na região do infravermelho que no visível, fazendo com que o total de radiação transmitida seja baixa, e a relação entre a transmitância da luz visível e o fator solar (Tv/FS) desses materiais sejam mais baixas como mostra na Figura 4, característica desfavorável para o uso em climas quentes. Além disso, a maioria dos policarbonatos apresentam uma alta absorção da radiação, ilustrado na Figura 5, o que pode causar desconforto localizado devido à alta temperatura radiante deles quando sofrem incidência da radiação solar.

Figura 4. Relação entre a Transmitância da Luz Visível e o Fator Sola (Tv/FS) (SANTOS et al., 2018).

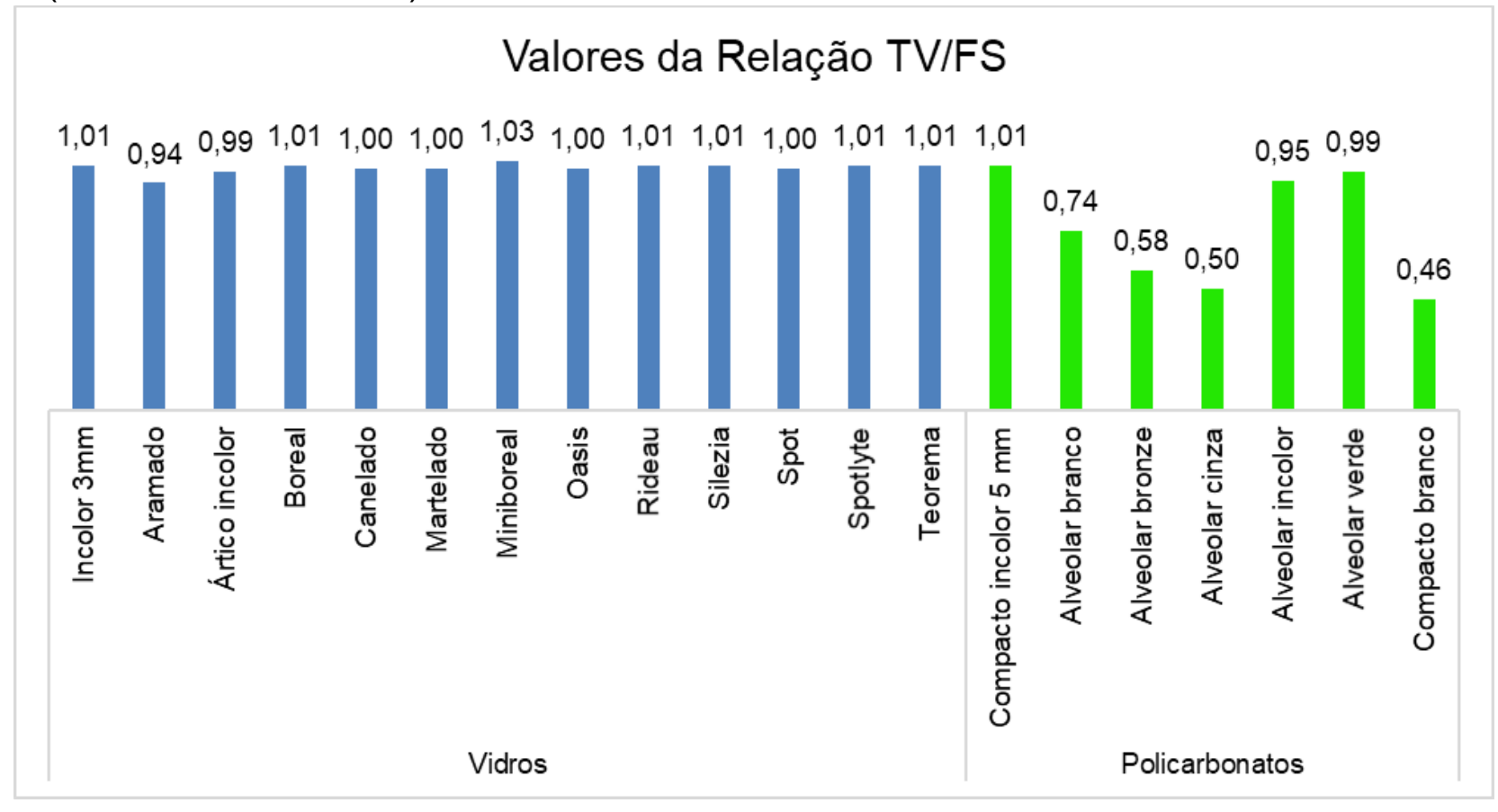

Em comparação entre os vidros e policarbonatos translúcidos, os vidros transmitem mais energia na região do visível e é menor no infravermelho, aumentando a relação (Tv/FS), sendo a melhor opção em termos de conforto térmico e luminoso, que os policarbonatos (SARDEIRO; CARAM, 2009).

Levando em consideração a maior absorbância nos policarbonatos, que em estudo, o material transmite uma parcela muito pequena na radiação do UV, transmite um maior percentual de energia na região do infravermelho comparada com região do visível, e que na relação de ganho de luz com o calor, o vidro se destacou com os melhores resultados com TV/FS próximo de um por transmitir mais energia no visível que no infravermelho, o policarbonato em geral não é o material mais adequado para garantir um conforto térmico e luminoso. 
Figura 5 - Absorbância total dos vidros e policarbonatos (SANTOS et al., 2018).

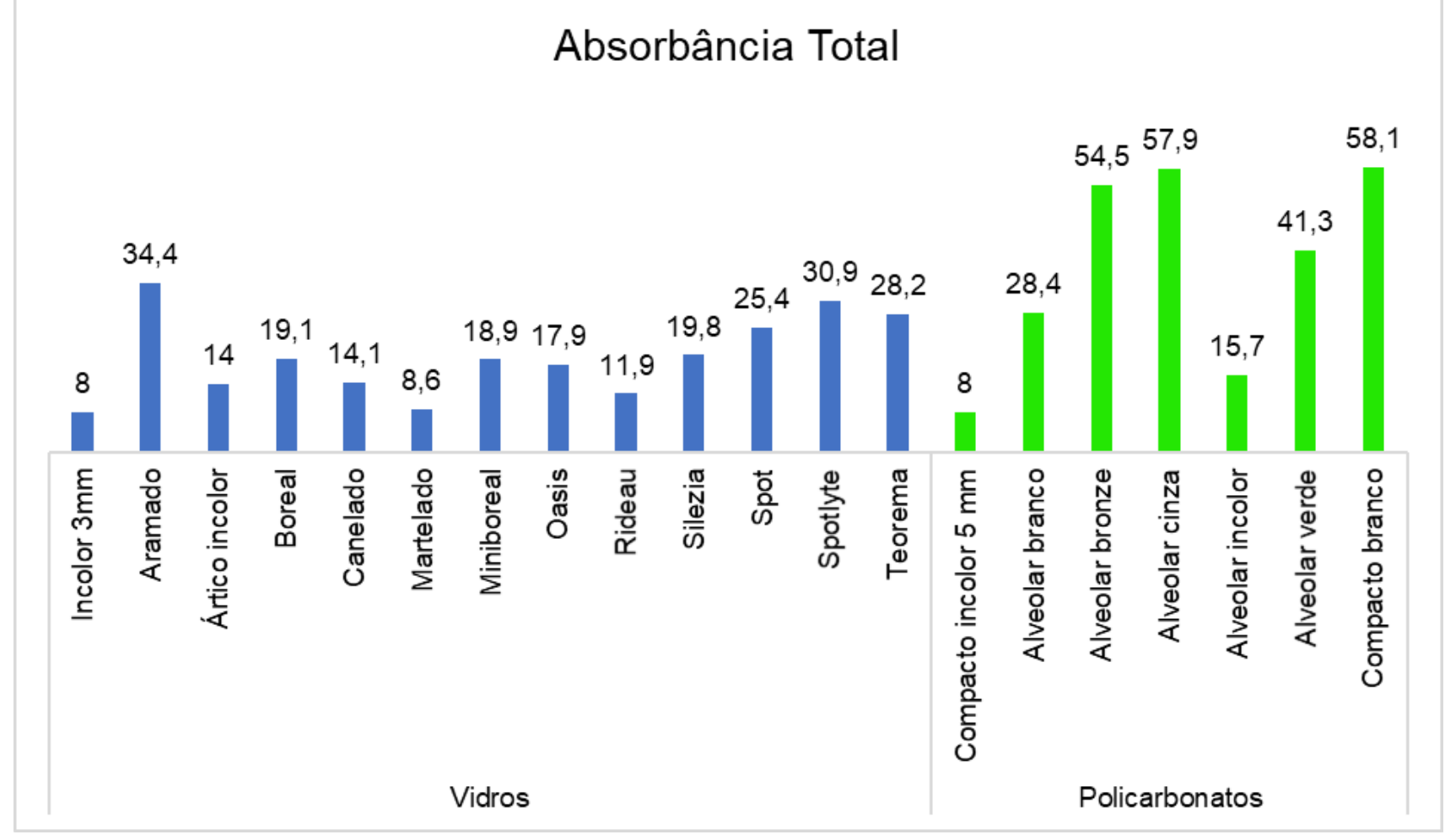

\section{RESISTÊNCIA DO MATERIAL}

A resistência dos materiais é a capacidade do material de resistir a uma força a ele aplicada. As superfícies transparentes têm como função principal a proteção das edificações, contra a ação das intempéries, atendendo às funções utilitárias, estéticas e econômicas. O material a ser utilizado para construir estas estruturas, deve ser resistente ao impacto, possuir resistência a intempéries, boa resistência química e térmica, e ser auto extinguível, além de outros fatores que são considerados como transmissão de luz e o calor que é transmitido para o ambiente.

\section{Resistência ao Impacto}

A capacidade de um determinado material de absorver energia do impacto está ligada à sua tenacidade, que por sua vez está relacionada com a sua resistência e ductilidade. O ensaio de resistência ao choque dá informações da capacidade do material absorver e dissipar essa energia.

Alguns vidros passam por tratamentos térmicos ou químicos para aumentar sua resistência, um exemplo de material é vidro temperado. Como resultado desse tratamento adicional, ele se torna de quatro a cinco vezes mais forte que o vidro recozido normal. É amplamente utilizado entorno do edifício, como fachadas e janelas por exemplo, e sistemas interiores de edifícios, devido à sua elevada resistência ao impacto (KUA; LU, 2016a).

De acordo com (KUA; LU, 2016b) o vidro temperado pode sofrer fratura espontânea 
em raras ocasiões devido à expansão de partículas de impurezas, que podem ser causadas pela expansão das partículas de sulfeto de níquel, ou pela expansão térmica das partículas de silício presentes no vidro. Esta quebra espontânea levou a mais rigorosas orientações sobre o vidro de segurança em todo o mundo e a necessidade de para materiais alternativos, e o policarbonato é um dos materiais que cada vez mais usado para substituir o vidro tradicional devido a seu peso leve, capacidade de transmissão de luz e isolamento potencial (KUA; LU, 2016b).

O policarbonato apresenta melhores resistências ao impacto quando comparado ao vidro. Sardeiro (2009) destaca que o uso do policarbonato devido a sua alta resistência e eficiência, vem aumentando significativamente. A resistência ao impacto do policarbonato é 250 vezes maior que a do vidro recozido e 30 vezes maior que o acrílico, e ainda apresenta a possibilidade de sua conformação a frio, permitindo uma maior liberdade de projeto, característica não pertinente ao vidro (SARDEIRO; CARAM, 2009).

O policarbonato mantém a sua resistência ao impacto numa larga escala de temperatura e mesmo em condições ambientais severas, suporta temperaturas entre - 50 ${ }^{\circ} \mathrm{C}$ até $+135^{\circ} \mathrm{C}$ e tem boas propriedades ópticas aliadas à alta resistência a exposição solar (radiação UV) (RIBEIRO; PARAÍBA, 2015).

Levando em consideração a escolha do material por sua resistência ao impacto o policarbonato se destaca. $\mathrm{O}$ vidro é muito bom para ser aplicado em sistemas interiores de edifícios e como fachadas e janelas, mas para locais onde é necessária uma maior segurança, ou que possui uma variação grande de temperatura e que passe por condições ambientais mais severas, o policarbonato é considerado mais adequado.

\section{Resistência Térmica}

Devido a altíssimas pressões e temperaturas no interior do sol, reações nucleares de fusão acontecem, onde dois núcleos de átomos de hidrogênio se transformam em núcleo de hélio, convertendo massa em energia e liberando a radiação solar e gerando uma potência de $3,9 \times 10^{26} \mathrm{~W}$. Desta, somente $1.370 \mathrm{~W} / \mathrm{m}^{2}$ chega à atmosfera, nomeada como constante solar (LAMBERTS; AUGUSTO; VECCHI, 2012).

O Sol é uma importante fonte de calor, e sempre haverá ganhos de energia onde tiver incidência dos seus raios, e estes ganhos variam de acordo com a transferência de calor através dos diferentes componentes da estrutura e do fluxo de ar por ventilação e/ou infiltração. Essa troca de calor depende das propriedades térmicas dos seus componentes, tais como resistência térmica, capacidade térmica, condutividade térmica, absortividade, refletividade e calor específico, e pelas variáveis climáticas aos quais estão expostos, principalmente radiação solar, temperatura do ar, vento e umidade relativa de ar (SARDEIRO; CARAM, 2009).

Para Sardeiro (2007), um dos fatores de avaliação de desempenho de superfícies translúcidas é o fator solar (FT), onde ele define como somatório entre parcela de radiação que atravessa o vidro diretamente e a parcela que é absorvida pelo vidro e reenviada para o ambiente interno. Através do FT dele sabe-se a quantidade de energia que atravessa o material, chegando ao interior do ambiente. Para um vidro simples de $3 \mathrm{~mm}$ o fator solar, ilustrado na Figura 6 , é de 0,87 ; isso significa que, $87 \%$ da radiação solar incidente sobre o vidro penetra no ambiente. Portanto, quanto maior o fator solar, maior a quantidade de energia transmitida. 
Figura 6. Valor do Fator Solar para diferentes tipos de vidros.

\begin{tabular}{|c|c|c|}
\hline \multicolumn{2}{|c|}{ Superfícies Separadoras } & Fator Solar \\
\hline \multirow{5}{*}{ Vidros } & $\begin{array}{c}\text { Transparente (simples) } \\
3 \mathrm{~mm} \\
6 \mathrm{~mm} \\
\end{array}$ & $\begin{array}{l}0,87 \\
0,83\end{array}$ \\
\hline & $\begin{array}{c}\text { Transparente (duplo) } \\
3 \mathrm{~mm} \\
\end{array}$ & 0,75 \\
\hline & $\begin{array}{c}\text { Cinza (fumê) } \\
3 \mathrm{~mm} \\
6 \mathrm{~mm} \\
\end{array}$ & $\begin{array}{l}0,72 \\
0,60\end{array}$ \\
\hline & $\begin{array}{l}\text { Verde } \\
3 \mathrm{~mm} \\
6 \mathrm{~mm} \\
\end{array}$ & $\begin{array}{l}0,72 \\
0,60\end{array}$ \\
\hline & $\begin{array}{l}\text { Reflexivo } \\
3 \mathrm{~mm}\end{array}$ & $0,26-0,37$ \\
\hline
\end{tabular}

Fonte: Sardeiro, 2007

Analisando os dados da Figura 7, os policarbonatos translúcidos ensaiados em trabalho de Santos et al. (2018), apresentaram valores de Fator Solar (FS) variando entre $75,4 \%$ no tipo alveolar incolor e de $47,7 \%$ no compacto branco. Esses valores são mais baixos do que os encontrados para o vidro, como podemos observar na Figura 6.

Figura 7. Valores do Fator Solar para diferentes tipos de policarbonatos (SANTOS et al., 2018).

Fator Solar (\%)

Policarbonato

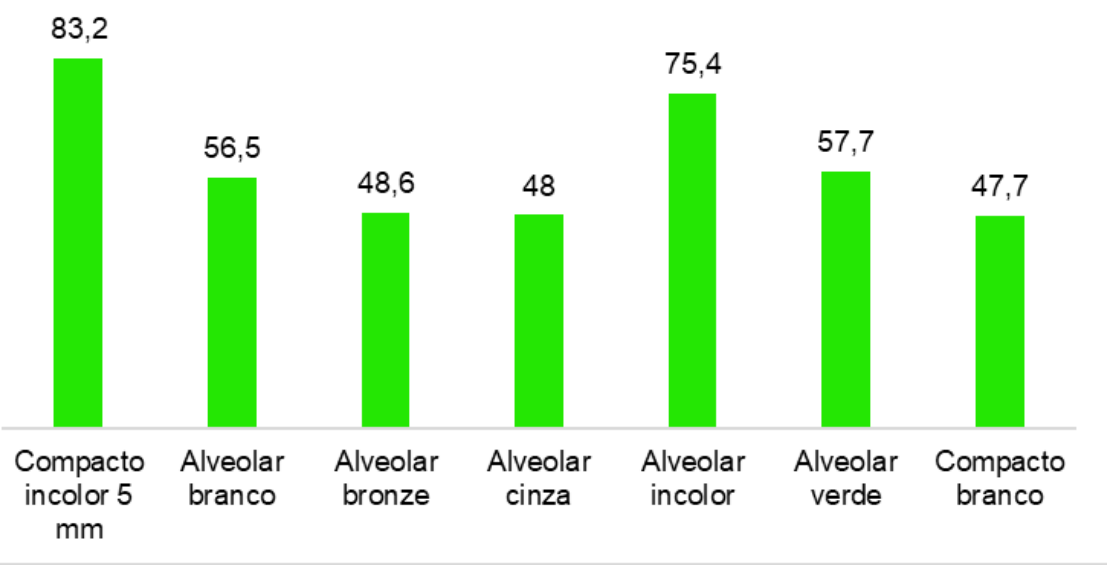

O vidro é considerado um mal condutor, ele oferece uma resistência na passagem de calor. Portanto se aquecermos um lado de uma placa ela irá dilatar e levará um certo tempo para aquecer o outro lado (AKERMAN, 2000). Atualmente de acordo com o PORTAL (2019), o policarbonato é um condutor pior que o vidro.

Assim quando o lado que está mais quente de um dos materiais se dilatar, gera um uma tensão, e se esta for acima da capacidade do material, ele pode se romper. Portanto, quanto maior a dilatação térmica, menor a resistência do material, quando há mudanças bruscas de temperatura (AKERMAN et al., 2009).

Para falar sobre resistência térmica é importante entrar no conceito de transição 
vítrea (Tg) que seria a passagem do material para uma fase com maior mobilidade das moléculas, que em alguns casos pode ser chamada de fase líquido super-resfriado como mostra a Figura 8, onde $T_{L}$ é o ponto de fusão do material.

Figura 8. Representação da variação do volume específico em função da temperatura.

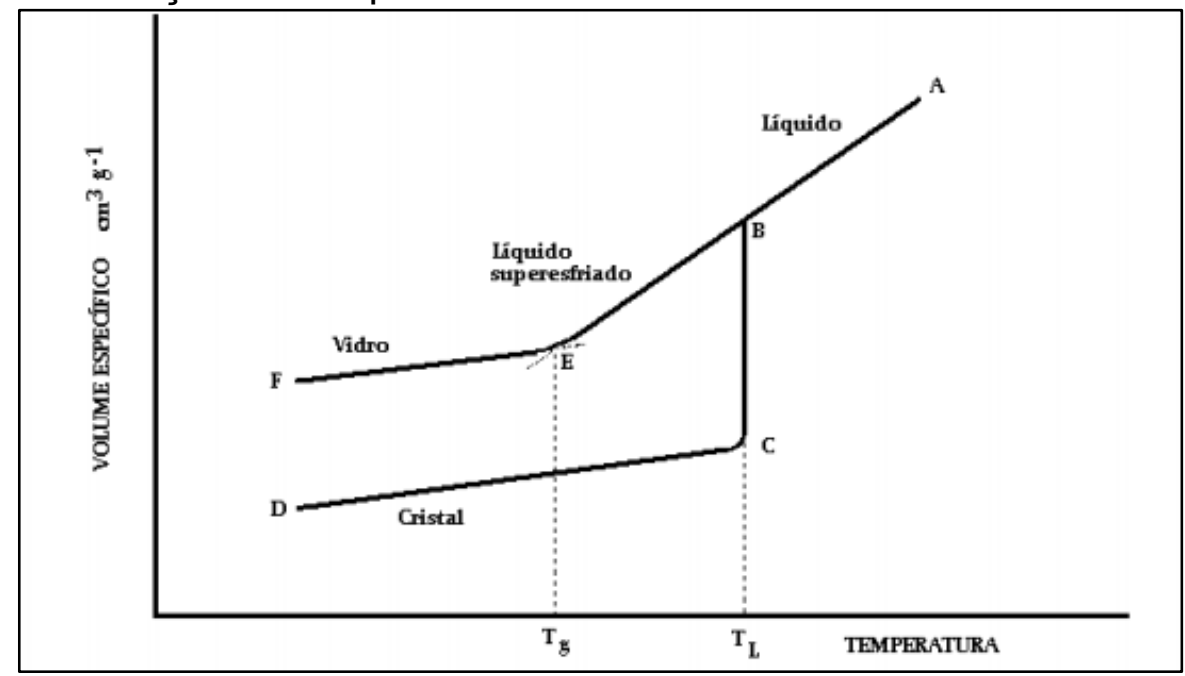

Fonte: Akerman et al., 2009

Observando o gráfico da Figura 8, podemos perceber que quando ocorre a diminuição gradativa da temperatura do material em estado líquido até chegar na temperatura $\mathrm{T}_{\mathrm{L}}$, o material pode passar por dois processos diferentes, a formação do cristal, onde acontece uma enorme redução no volume (formando uma fase cristalina), ou o mesmo passa para o estado liquido super resfriado mantendo a taxa de contração no volume do liquido inicial até chegar na temperatura e transição vítrea (Araujo 1997).

A sílica $\left(\mathrm{SiO}_{2}\right)$ que é a matéria prima básica para composição do vidro possui Tg variando de $1500 \mathrm{~K}$ à $2000 \mathrm{~K}$, o vidro de janela $\left(\mathrm{Na}_{2}-\mathrm{CaO}-\mathrm{SiO}_{2}\right.$ ) varia $800-820 \mathrm{~K}$ (Araujo 1997). Diferente do policarbonato (PC) que possui Tg de aproximadamente $425 \mathrm{~K}$, que ainda sim é considerada alta, e uma alta estabilidade térmica em temperaturas que podem chegar à $580 \mathrm{~K}$ (Sales et al. 2017).

O que mais afeta o vidro e o policarbonato em projetos de coberturas transparentes, é a luz solar e o comportamento das suas radiações (infravermelho, luz visível e ultravioleta) frente as coberturas, mas considerando este comportamento - onde parte dela é refletida, transmitida e absorvida - e a temperatura de transição vítrea, pode-se dizer que só a radiação solar não é suficiente para afetar termicamente ambos os materiais e que o vidro é mais resistente termicamente que o policarbonato.

Em casos de incêndio, a resistência do vidro convencional ao fogo é muito baixa, por isso, já existem vidros resistentes ao fogo chamados de vidros antifogo, composto por várias lâminas intercaladas com material químico transparente, que se funde e dilata em caso de incêndio (ABRAVIDRO 2019). Já a resistência do policarbonato ao fogo é consideravelmente maior comparada aos plásticos comuns, o material queima com dificuldade e requer uma contínua alimentação de uma fonte de combustão externa para conservá-lo queimando. Os gases produzidos em combustão não são especialmente tóxicos, e são muito parecidos com os produzidos na queima da madeira (GIACOMINI, 
2012).

\section{Durabilidade Química}

Uma das principais características do vidro é a sua elevada durabilidade química. Alguns vidros milenares permanecem até os dias atuais sem apresentarem sinais de deterioração. Os vidros são muito resistentes a soluções ácidas, com exceção ao ácido fluorídrico (HF), e levemente básicas $(\mathrm{pH}<9)$, porém são atacáveis por soluções de alta basicidade.

Levando em consideração os vários tipos de vidros, e que suas composições podem variar, a Figura 9 ilustra de uma forma qualitativa o comportamento do vidro em relação as suas propriedades em função do aumento de um de seus óxidos. Destacando o óxido de sódio $\left(\mathrm{Na}_{2} \mathrm{O}\right)$, cujo aumento da concentração na matriz do vidro causa um aumento na sua fluidez, expansão e solubilidade, mas por outro lado diminui a sua durabilidade, e o óxido de alumínio $\left(\mathrm{Al}_{2} \mathrm{O}_{2}\right)$ que ao contrário do $\mathrm{Na}_{2} \mathrm{O}$, aumenta a viscosidade do vidro e a sua durabilidade.

Figura 9 - Variação das propriedades dos vidros com o aumento da concentração de alguns óxidos. DEVITRIFICAÇÃo

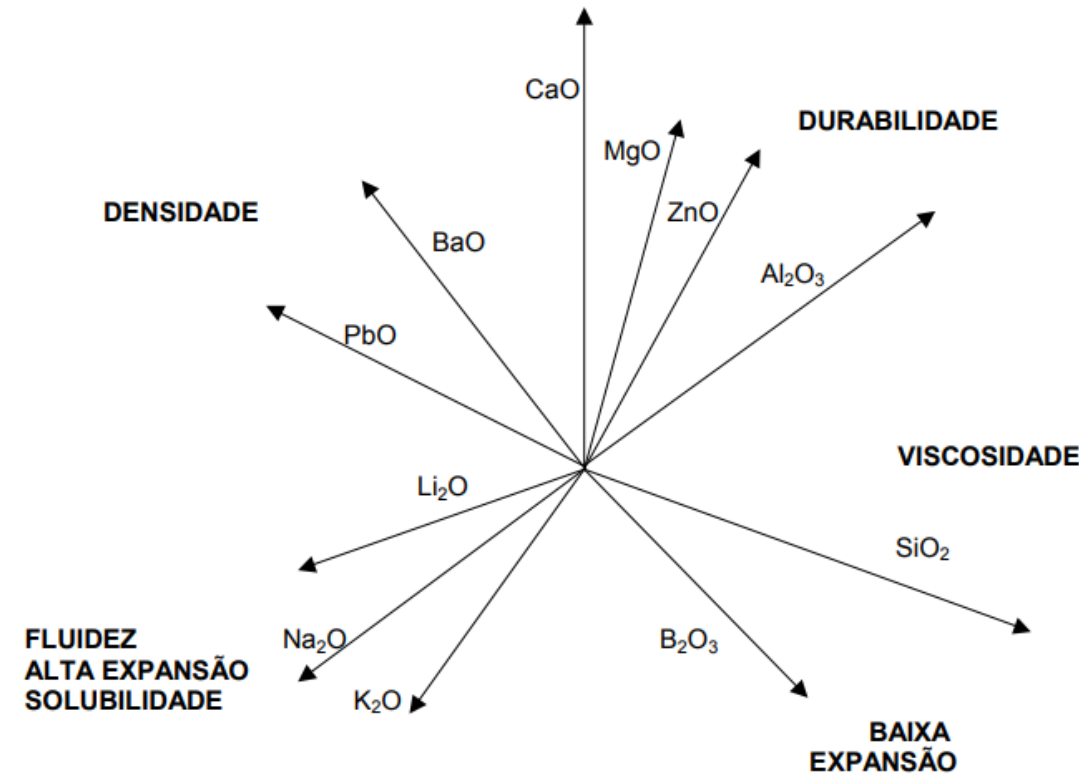

Fonte: Akerman et al., 2009

Já o policarbonato é razoavelmente resistente à ataques químicos e condições adversas que podem ser encontradas em construções. É resistente ao ataque de ácidos diluídos, sais inorgânicos e álcool, e não é afetado por cimento ou gesso (GIACOMINI, 2012).

Alguns agentes como cloreto de etileno, clorofórmio, tetracloroetano e pridina podem causar dissolução ou inchamento parcial do policarbonato. Outros agentes deformantes são benzeno, clorobenzeno, tetralina, acetona, acetato de etilo, acetonitrila e tetracloreto de carbono. Para água, a resistência do policarbonato é considerada boa até $60^{\circ} \mathrm{C}$. Em 
temperaturas mais altas, ocorre deformação dele, o efeito depende do tempo e da temperatura. Portanto, não deve ser exposto a água quente por longos períodos (PALRAM PLASTIC, 2019).

Para polímeros e plásticos a luz UV (ultravioleta) tem energia suficiente para causar alterações químicas nos polímeros. Existem três tipos desta radiação: UV-A cujo comprimento de onda está na faixa de 315 a $400 \mathrm{~nm}$, UV-B com faixa de 280 a $315 \mathrm{~nm}$, e UV-C com menor comprimento de onda entre 200 a $280 \mathrm{~nm}$. Sabendo que o UV-B e UVC são absorvidos pela atmosfera, a radiação de maior relevância para o intemperismo natural é a radiação UV-A (McKEEN, 2019).

O destino da luz absorvida é importante no processo de intemperismo. A fotodegradação começa principalmente quando a luz ultravioleta atinge o polímero e remove um átomo de hidrogênio, gerando um radical instável e reativo que pode se envolver em vários processos foto físicos ou fotoquímicos, para alcançar uma menor energia (McKeen 2019), ou seja, a radiação UV é capaz de destruir as ligações entre as moléculas dos polímeros que ao longo do tempo provocam alterações em suas propriedades mecânicas e físicas.

A refração é a mudança na velocidade de uma onda ao atravessar a fronteira entre dois meios com diferentes índices de refração e geralmente causa uma mudança na direção. A reflexão da radiação na superfície do material é o resultado mais desejado para prevenir ou reduzir a degradação, porque a energia da luz é redirecionada para o espaço circundante e, portanto, não afeta o material plástico. Observa-se na Figura 10 o comportamento da onda em diferentes níveis de refração (McKEEN, 2019).

No filme espesso com pigmento de índice de refração alto, observa-se que a luz é desviada mais do que no filme contendo o baixo índice de refração, com o resultado a luz percorre um caminho mais curto no filme e não penetra tão profundamente. Em ambos os filmes mostrados nas imagens $A$ e $B$ da Figura 10, não há partículas absorventes, e praticamente toda a luz incidente é retornada para a superfície. Entretanto, para o filme de espessura mais fina, Imagens C e D da Figura 10, a luz pode passar através do filme, parecendo mais transparente (McKEEN ,2019).

O índice de refração do policarbonato é igual a "1,59" de acordo com McKeen (2019). Os vidros comuns têm uma reflexão muito pequena no visível e no infravermelho, com índice de refração diminuindo linearmente de 1,5 a 1,2 entre $400 \mathrm{~nm}$ e $7000 \mathrm{~nm}$ (Krenzinger, 2006).

O vidro é o material mais utilizado na cobertura de equipamentos de captação de energia solar por ser transparente para a luz visível e para a maior parte da radiação solar e ao mesmo tempo resistente aos raios ultravioletas. Ele possuí variações no índice de refração fazendo com que tenham maior coeficiente de reflexão justamente na faixa espectral de operação das câmeras termográficas (KRENZINGER, 2006).

A Figura 11 feita com dados de Santos et al. (2018), observa-se a absorbância dos policarbonatos estudados é consideravelmente maior que a dos vidros, para faixas do UV, sendo esta responsável por toda a fotodegradação dos materiais expostos ao ar livre. Podemos considerar o policarbonato mais vulnerável ao intemperismo natural, resultando no amarelamento e na deterioração das propriedades do material. 
Figura 10. Comportamento da onda em diferentes índices de refração e espessura do filme. (A) em um filme espesso com alto índice de refração, (B) em um filme espesso com baixo índice de refração, (C) em um filme fino com alto índice de refração e (D) Em um filme fino com baixo índice de refração.

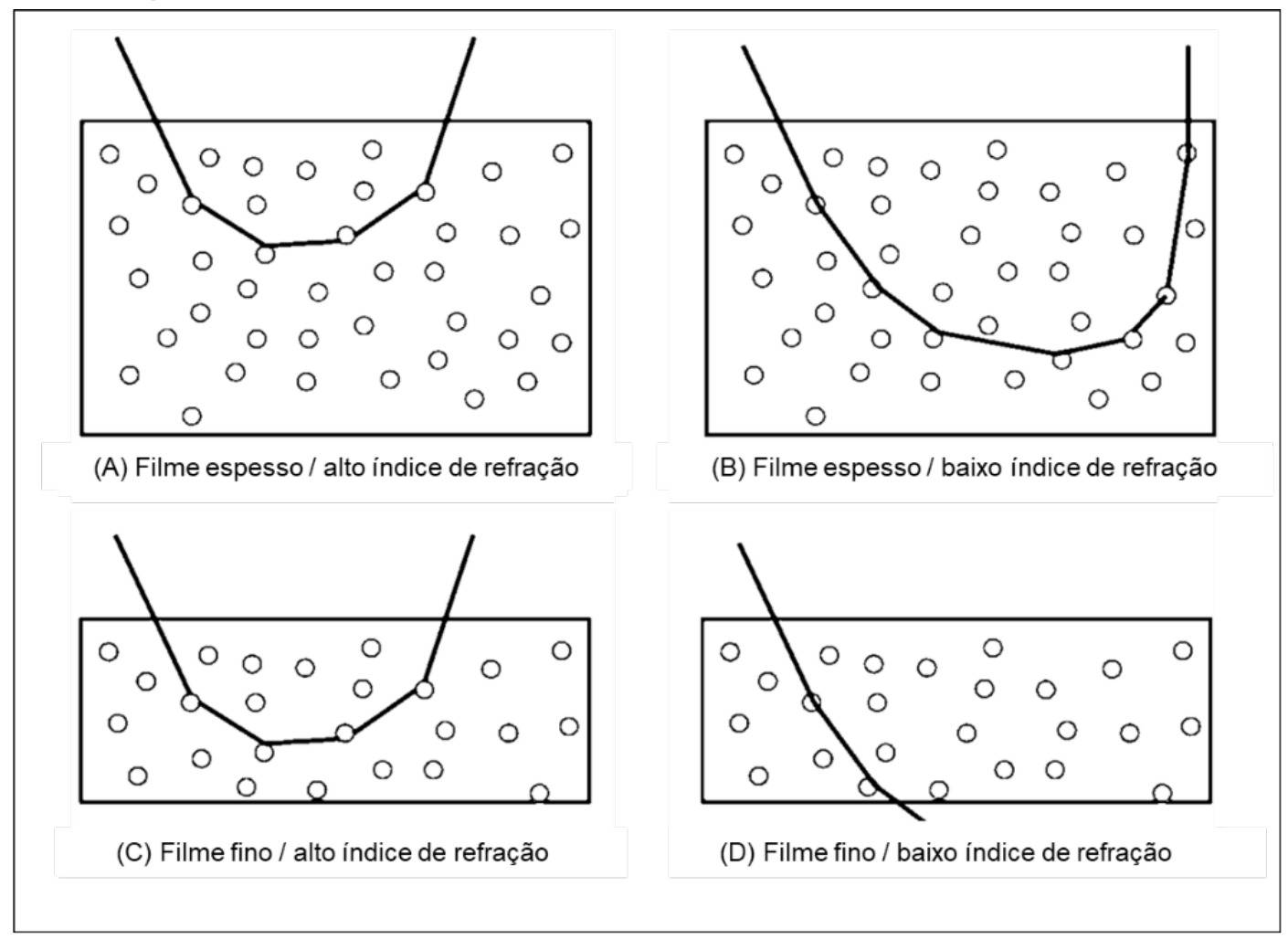

Fonte: McKeen, 2019

Figura 11. Valores da absorbância da radiação ultravioleta em diferentes tipos de vidros e policarbonatos.

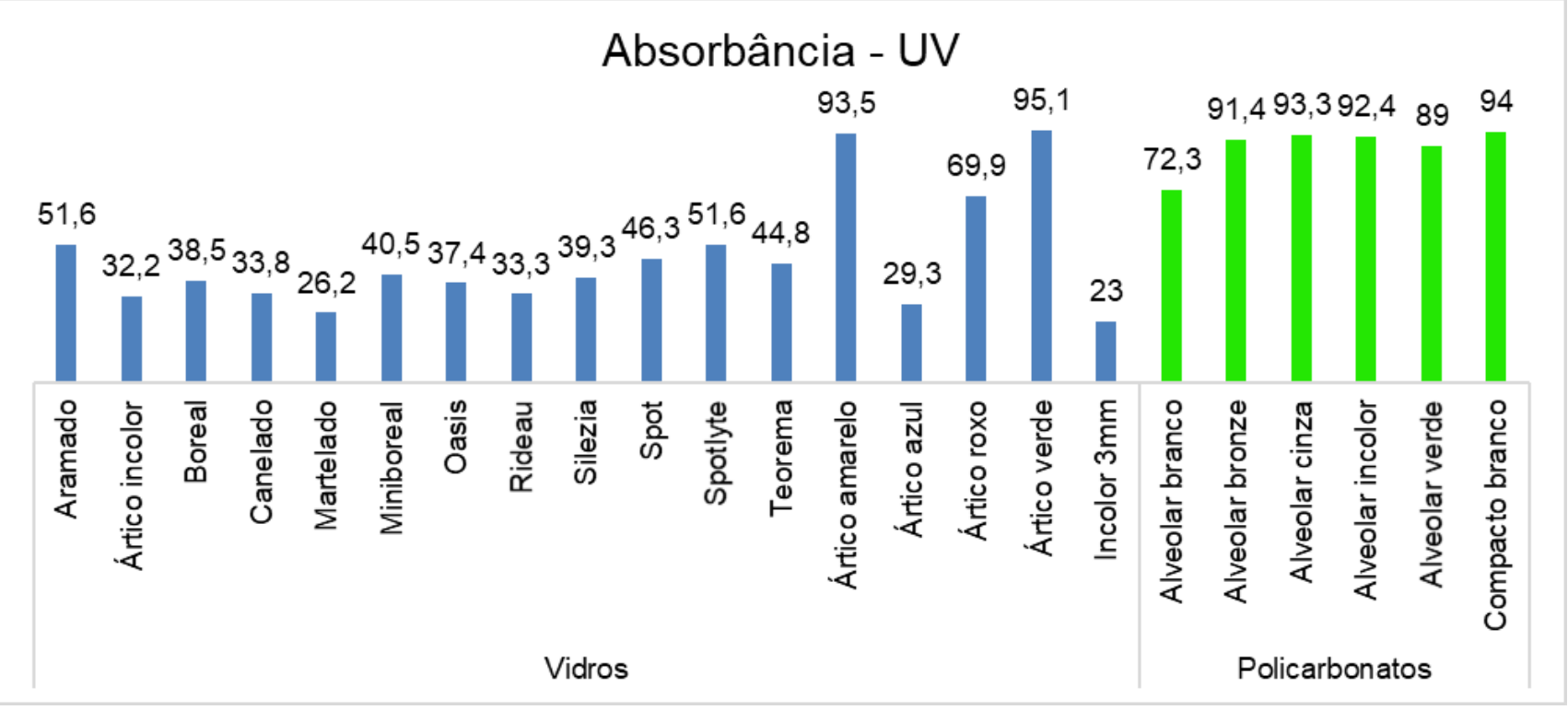




\section{Propriedades do Material}

De acordo com os dados encontrados na bibliografia referente a comparação feita entre o vidro e o policarbonato quanto a sua resistência e sua eficiência em manter um ambiente confortável, desenvolveu-se a Tabela $\mathbf{4}$ comparando as principais propriedades estudadas.

Tabela 4 - Tabela comparativa do vidro e policarbonato.

\begin{tabular}{lcc}
\hline \multicolumn{1}{c}{ Propriedades } & Vidro & Policarbonato \\
\hline Resistência ao Impacto & $\begin{array}{c}\text { Vidro temperado }-5 \mathrm{x} \\
\text { maior que o vidro cozido }\end{array}$ & $\begin{array}{c}250 \times \text { maior que o vidro } \\
\text { cozido }\end{array}$ \\
$\begin{array}{l}\text { Índice de Refração } \\
\text { Temp. Máx de Trabalho }\end{array}$ & 1,52 & 1,586 \\
Calor Específico & $520^{\circ} \mathrm{C}$ & $135^{\circ} \mathrm{C}$ \\
Condutividade Térmica & $1,02 \mathrm{~W} / \mathrm{m}^{\circ} \mathrm{C}$ & $0,19-0,21 \mathrm{~W} / \mathrm{m}^{\circ} \mathrm{C}$ \\
Coeficiente de expansão & $0,54-7,9 \times 10^{-6} /{ }^{\circ} \mathrm{C}$ & $66-67 \times 10^{-6} /{ }^{\circ} \mathrm{C}$ \\
Dureza (Escala de Moh) & $5,4-5,8$ & 4 \\
Inflamabilidade & Baixa resistência ao fogo & Razoável resistência ao fogo \\
\hline
\end{tabular}

De acordo com a tabela, pode-se destacar que o policarbonato é mais vantajoso que o vidro nas propriedades de resistência ao impacto onde o mesmo é 250 vezes mais resistente que o vidro cozido normal, na inflamabilidade onde o vidro tem baixa resistência em situações onde há fogo, que neste caso é necessário vidros feitos especificamente para isso, e para condutividade térmica onde o policarbonato é um melhor isolante que o vidro, mas levando em consideração a resistência do material, se a condutividade térmica é menor, maior o tempo da passagem de calor de um lado para o outro, podendo fazer com que um lado do material sofra uma expansão levando o mesmo a quebra.

No índice refrativo e no calor específico a diferença é muito pequena entre ambos os materiais. Por outro lado, o vidro é um material que apresenta maior resistência e durabilidade frente aos diferentes tipos de intempéries, pois apresenta maior resistência à temperatura e a soluções ácidas e básicas e menos expansivo.

\section{CONCLUSÕES}

Neste artigo foi possível relacionar e comparar materiais a base de vidro e policarbonato com foco em diversos parâmetros considerados importantes para o uso em construções que apresentam regiões transparentes. Quando se fala em conforto térmico e luminoso, o vidro se mostrou ser o material mais recomentado frente aos comportamentos das radiações solares em contato com ele e por apresentar melhores resultados nas relações de ganho de luz e calor (TV/FS). O policarbonato se destacou por ser um material mais eficiente e seguro quando se trata de resistência ao impacto, e em casos de incêndio, mostrando ser um material auto extinguível, onde ocorre a queima com 
dificuldade e requer uma contínua alimentação de uma fonte de combustão externa para conservá-lo.

Quanto à durabilidade química, os vidros são muito resistentes a soluções ácidas, com exceção ao ácido fluorídrico $(\mathrm{HF})$, e levemente básicas $(\mathrm{pH}<9)$, porém são atacáveis por soluções de alta basicidade. E o policarbonato é resistente a ataque de ácidos diluídos, sais inorgânicos e álcool. Deve-se ter cuidado com a exposição a água quente por longos períodos, pois pode causar deformações. O policarbonato também apresenta ter um percentual maior de absorção de radiação UV, responsável pelo intemperismo natural, quando comparado ao vidro, podendo resultar e amarelamento e deterioração das propriedades do material.

\section{REFERÊNCIAS}

ABRAVIDRO Vidro Antifogo. Disponível em: https://abravidro.org.br/vidros/vidroantifogo/\%3E. Acesso em: maio 2019.

AKERMAN, M. et al. Reciclagem de Vidro Como Alternativa Para Concreto. Revista Concreto \& Construções. v. 51, n. 53, p. 397-408. 2013. Disponível em: http://www.certev.ufscar.br/documentos/arquivos/introducao-ao-vidro.

ARAUJO, E. B. Vidro: Uma Breve Historia, Técnicas de Caracterização e Aplicações $\mathrm{Na}$ Tecnologia. Revista Brasileira de Ensino de Física. v. 19, n. 325, p. 325-29, 1997.

BARROS, C.; VIANA, T. Apostila de Vidros - Materiais de Construção Edificações. Instituto Federal de Educação, Ciência e Tecnologia Sul-Rio-Grandense, Campus Pelotas. p. 1-10, 2010.

BELARMINO, R. Vidro Temperado ou Laminado Para Envidraçamento De Sacadas?" Disponível em: http://www.solidsacadas.com.br/blog/vidro-temperado-ou-laminado-paraenvidracamento-de-sacada. Acesso em: maio 2019.

BRASIL. Ministério de Minas e Energia. Empresa de Pesquisa Energética (EPE). Anuário Estatístico de Energia Elétrica: 2018 - Ano Base 2017. Disponível em: http://epe.gov.br/sites-pt/publicacoes-dadosabertos/publicacoes/PublicacoesArquivos/publicacao-160/topico-168/Anuario2018vf.pdf. Acesso em: maio 2019.

CEBRACE ENCICLOPEDIA. Disponível em: http://www.cebrace.com.br/\#!/enciclopedia. Acesso em maio 2019

GIACOMINI, E. 2012. Material, O Vidro. Dissertação de mestrado - Faculdade de Engenharia da Universidade do Porto. 2008.

IMBELLONI, R. Vidro - O Mercado para Reciclagem. Disponível em:

http://cempre.org.br/artigo-publicacao/ficha-tecnica/id/6/vidro. Acesso em maio 2019.

KRENZINGER, A. Aplicações da termografia na Análise Térmica de Sistemas De Conversão de Energia Solar. Avances en Energías Renovables y Medio Ambiente. 
v.10, n. 3, p. 77-84, 2006.

KUA, H. W.; LU, Y. Environmental Impacts of Substituting Tempered Glass with Polycarbonate in Construction - An Attributional and Consequential Life Cycle Perspective. Journal of Cleaner Production. v. 137, p. 910-21, 2016.

LAMBERTS, R. A. A. et al. Conforto E Stress Térmico. Centro Tecnológico Departamento De Engenharia Civil. Santa Catarina 2012

MALLMANN, B. M. Análise Computacional do Impacto da lluminação e dos Vidros na Demanda Energética de um Edifício Comercial. Trabalho de Diplomação apresentado ao Departamento de Engenharia Civil da Escola de Engenharia da Universidade Federal do Rio Grande do Sul. 2011.

McKEEN, L. W. Introduction to the Weathering of Plastics in the Effect of UV Light and Weather on Plastics and Elastomers, Elsevier, p. 21-47. 2019.

PAIXÃO, R. C.; CASTRO, A. P. A. S. Avaliação Do Desempenho Térmico De Coberturas De Policarbonato E Acrílico: Estudo De Caso No Campus Da Unimep Em Santa Bárbara Doeste. In: 19 Congresso de Iniciação Científica, p. 1-7. 2011.

PALRAM PLASTIC. Resistencia Química de Los Productos de Policarbonato Chemical Resistance of Polycarbonate. Disponível em: https://palram.mk401.signatureit.com/datafiles/Palram_Sp_PC_Chemical_Resistance.pdf. Acesso em maio 2019.

PIATTI, T. M.; RODRIGUES, R. A. F. Plásticos: Características, Usos, Produção e Impactos Ambientais. Edufal -. Maceió - AL. 2005.

PORTAL. Policarbonato. Disponível em: https://www.portalsaofrancisco.com.br/meioambiente/policarbonato. Acesso em: maio 2019.

RECICLOTECA. Vidro: História, Composição, Tipos, Produção e Reciclagem. Disponível em: http://www.recicloteca.org.br/material-reciclavel/vidro. Acesso em: maio 2019.

RESINEX GROUP. Policarbonato.Disponível em: https://www.resinex.pt/tipos-depolimeros/pc.html. Acesso em: maio 2019.

RIBEIRO, V. C.; Avaliação Da Eficiência De Um Coletor Solar Plano Usando Policarbonato Em Substituição Ao Vidro. Campina Grande Paraíba. 2015

RIFFEL, C. F. et al. Estudo de Viabilidade Técnica e Custos Para Execução de Coberturas com Telhas Metálicas Termoisolantes, Fibrocimento e Policarbonato. In Uceff - Anais de Engenharia Civil, v. 1, p. 57-74. 2017.

SALES, D. H. O. et al. Estudo da Cristalinidade Induzida por Deformação Plástica no Policarbonato. Revista Militar de Ciência e Tecnologia Versão XXXIV. p. 26-28. 2017

DOS SANTOS, J. C. P. et al. Comportamento Ótico de Vidros e Policarbonatos 
Translúcidos Frente à Radiação Solar. Matéria (Rio de Janeiro) v.23, n .3. 2018.

SARDEIRO, P. S.; CARAM, R. M.. "Caracterização Ótica de Policarbonatos Visando o Conforto Térmico da Edificação. In: X Encontro Nacional e VI Encontro Latino Americano de Conforto No Ambiente Construido, v. 4, p. 24-30. 2009.

SARDEIRO, P. S. Parâmetros Para a Escolha de Superfícies Translúcidas Visando o Conforto Térmico e Visual Na Edificação. Tese de Doutorado apresentada a Comissão de Pós-Graduação da Faculdade de Engenharia Civil, Arquitetura e Urbanismo da Universidade Estadual de Campinas. 2007.

TOLEDO, B. G. Integração de lluminação Natural e Artificial: Métodos e Guia Prático Para Projeto Luminotécnico. Dissertação de Mestrado apresentada ao Programa de Pós-Graduação em Arquitetura e Urbanismo da Faculdade de Arquitetura e Urbanismo da Universidade de Brasília. 2008.

VIEIRA, N. I. M. Contribuição ao Estudo de Reciclagem de Policarbonato Advindo de Apreensão de Óculos Pela Policia Federal. Trabalho de Conclusão de Curso para a obtenção do grau de Engenharia de Materiais pela Universidade Federal do Rio Grande do Sul. 2014.

Recebido em: 09/08/2019

Aprovado em: 25/09/2019 